\title{
ORIGIN OF STREPTOMYCIN-RESISTANT VARIANTS OF TUBERCLE BACILLI
}

\author{
KOOMI KANAI, SHIgerU KATSUYAMA, AND KeN YANAGISAWA \\ Department of Tuberculosis, National Institute of Health, Tokyo
}

(Received: December 13th, 1955)

\section{INTRODUCTION}

The occurrence of bacterial resistance to chemotherapeutic agents has been extensively studied in recent years. Particularly, streptomycin resistance is a subject which has been attracting the special interest of workers on microbial genetics. Some investigators ${ }^{(1-4)}$ insisted that the spontaneous mutation and selection theory can explain the process of the development of streptomycin resistance, but some others ${ }^{(5-9)}$ supported the induced mutation theory as the most rational explanation for that phenomenon. The discussion is continued even now with endless controversy. The difficulty to reach a conclusive view of this problem is attributable to the fact that there has not been any suitable method to detect the presence of streptomycin-resistant mutants without bringing bacterial population into contact with streptomycin.

Concerning the case of tubercle bacilli, only a few experiments have ever been reported analyzing the origin of streptomycin-resistant variants from the genetical standpoint. Yegian and Vanderlinde(3), and Ushiba ${ }^{(10)}$ adopted the spontaneous mutation and selection theory for theoretical consideration of their experiments using tubercle bacilli, but Akiba(11), Yokota(9), Kimino(12), and Katsunuma(13) insisted the induced mutation theory stating that streptomycin has a property of mutagen of non-specific nature.

The present authors ${ }^{(14)}$ have reported previously that the spontaneous mutation and selection theory is applicable in order to explain the at first gradual and then rapid form of the resistance increasing curve in BCG from the frequency distribution curve of the possibly naturally-occurring mutants in this strain. According to their further studies(15), however, it was pointed out that such a low rate of occurrence of high-resistant cells $\left(1: 10^{7}-10^{8}\right.$ sensitive cells) is contradictory to the explanation that resistance development is merely due to the selection of them in the environment of streptomycin. Because, even with small inoculum in which the high-resistant cells can never be considered to be contained, the high resistance developed in serial passage through the culture media containing increasingly higher concentrations of streptomycin. 
Then, it was speculated that there may be at least two kinds of process in which tubercle bacilli acquire streptomycin resistance; the induced mutation in step-wise increase of resistance and the spontaneous mutation and selection in the case of one-step isolation of high resistant cells. In the present paper more detailed experiments were described as the third report of our studies on this problem.

\section{Methods AND MAterials}

Mycobacterial strain: H37Rv was used throughout the present experiments. This strain had been supplied by the Mayo Foundation by courtesy of Dr. Karlson.

Culture medium: In our previous experiments $(14,15)$, Kirchner's liquid or agar medium was principally used. This time, however, Ogawa's egg solid medium was employed because of the easiness of mass production. It was prepared as follows.

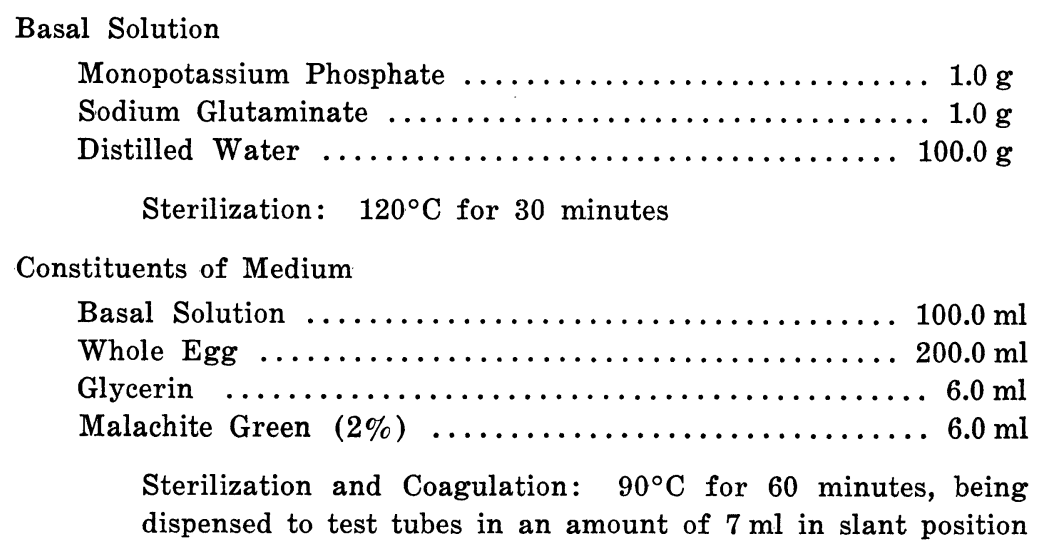

When added, streptomycin was dissolved in basal medium. But, as it is known that the concentration of streptomycin is reduced to one third of the original due to heating added during the preparation of the medium, the drug was mixed to the basal solution in an appropriate amount with due consideration to this fact.

Streptomycin: Streptomycin sulphate of known potency was used.

Preparation of bacterial suspension: Cultures on slants of Ogawa's medium were scraped together and put into a round flask of $300 \mathrm{ml}$ capacity containing 60 crystal balls of $7 \mathrm{~mm}$ in diameter. By rotating it manually with occasional adding of distilled water, the bacillary mass was ground to give a homogeneous suspension. 


\section{EXPERIMENTAL}

Experiment 1: Proportion of variants resistant to various concentrations of streptomycin in the original H37Rv culture and the cultures grown on Ogawa's medium containing low concentrations of streptomycin. Many slants of Ogawa media drug-free and containing streptomycin in 14 different concentrations ranging from 0.5 to $1000 \gamma$ per $\mathrm{ml}$ were prepared. On the other hand, a dense bacillary suspension was made from a 14 day culture of $\mathrm{H} 37 \mathrm{Rv}$ on the Ogawa medium, and then serial dilutions were prepared from this suspension by tenfold steps until a $1: 10^{6}$ dilution was obtained. Each of seven kinds of dilution thus prepared was inoculated to the slants in an amount of $0.1 \mathrm{ml}$, using two slants for each concentration of streptomycin. The slants inoculated were then incubated at $37^{\circ} \mathrm{C}$ for 10 weeks. In 24 days after inoculation, the growth on the $0.5 \gamma$ per ml slants inoculated with the original and the 1:10 diluted bacillary suspension was resuspended in distilled water and inoculated to slants of serial concentrations of streptomycin in just the same way as before. Again in 28 days, the same procedure was repeated using the growth on $1 \gamma$ per ml and $2 \gamma$ per ml slants. In 10 weeks after each inoculation, emergent colonies on these slants were counted and the results were summarized in Fig. 1, making

Fig. 1. Process of population increase of streptomycin resistant cells in H37Rv during the subculture experiment

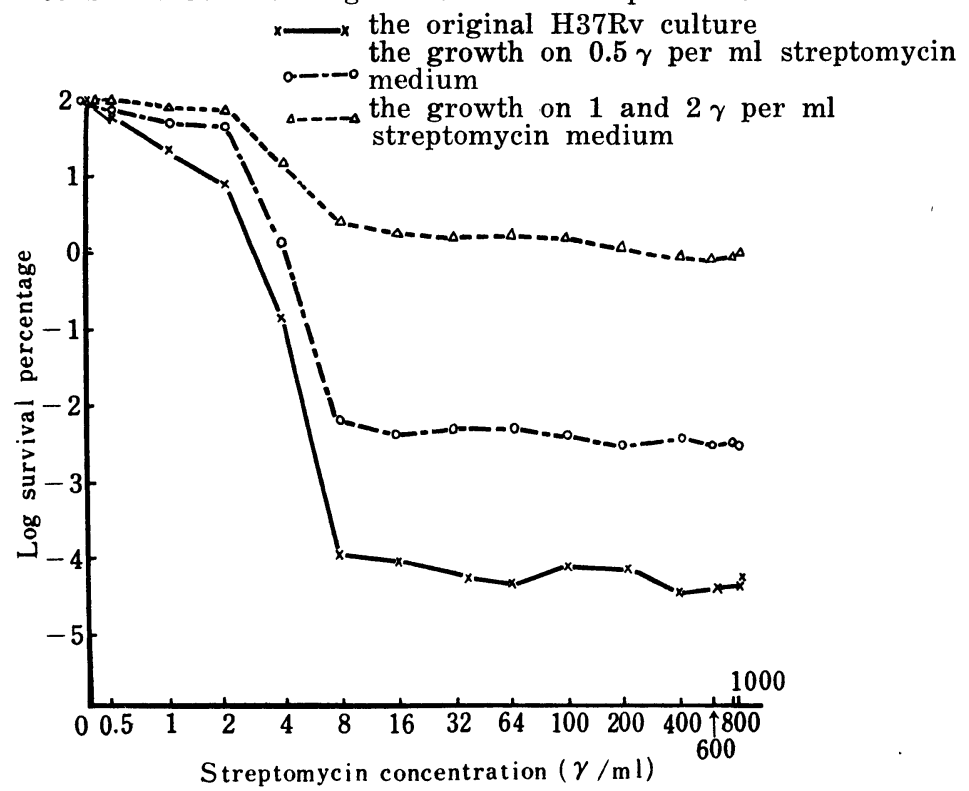

a curve plotting log survival percentages in each streptomycin concentration. As shown in this figure, the original strain of $\mathrm{H} 37 \mathrm{Rv}$ contained the variants resistant to streptomycin of $8 \gamma$ per $\mathrm{ml}$ or to higher concentrations in the rate 
of approximately $1: 10^{6-7}$ sensitive cells. On the other hand, the bacillary growth on the 0.5 or 1-2 $\gamma$ per $\mathrm{ml}$ streptomycin medium contained those resistant cells in much higher proportions. Worthy of mentioning was, however, that the curves of the above three cases were the same in the general form and particularly in the tendency running horizontally in the range from 8 to $1000 \gamma$ per ml. Table 1 shows the real numbers of emergent colonies in the slants inoculated with each dilution of the original H37Rv bacillary suspension. In this table the authors should like to point out the fact that there occurred many dysgonic colonies on the slants of $8 \gamma$ per ml only after the lapse of several weeks, which appeared to be the threshold concentration of streptomycin to permit the growth of intermediate resistant cells.

Table 1. Single step isolation of streptomycin resistant variants from H37Rv strain

\begin{tabular}{|c|c|c|c|c|c|c|c|c|c|c|c|c|c|c|c|c|}
\hline \multirow{2}{*}{$\begin{array}{c}\text { Culture } \\
\text { weeks }\end{array}$} & \multirow{2}{*}{ Inoculate } & \multicolumn{15}{|c|}{ Streptomycin concentration $(\gamma / \mathrm{ml})$} \\
\hline & & 0 & 0.5 & 1 & 2 & 4 & 8 & 16 & 32 & 64 & 100 & 200 & 400 & 600 & 800 & 1000 \\
\hline \multirow{7}{*}{5} & Original & H & W & Ht & H & + & 12 & 10 & 8 & 9 & 11 & 10 & 6 & 3 & 2 & 4 \\
\hline & $1: 10$ & Ht & & & H & + & 2.5 & 1. & 0 & 1 & 1 & 2 & 0 & 1 & 2 & 0.5 \\
\hline & $1: 10^{2}$ & H & W & H & + & 133 & 0.5 & 0 & 0 & 0 & 0 & 0 & 0 & 0 & 0 & 0 \\
\hline & $1: 10^{3}$ & \# & $\mathrm{Ht}$ & $H$ & $\perp$ & 16.5 & 0 & 0 & 0 & 0 & 0 & 0 & 0 & 0 & 0 & 0 \\
\hline & $1: 10^{4}$ & H & H & H & 20 & 1 & 0 & 0 & 0 & 0 & 0 & 0 & 0 & 0 & 0 & 0 \\
\hline & $1: 10^{5}$ & + & + & 40.5 & 5 & 0 & 0 & 0 & 0 & 0 & 0 & 0 & 0 & 0 & 0 & 0 \\
\hline & $1: 10^{6}$ & 23 & 17.5 & 4.5 & 0 & 0 & 0 & 0 & 0 & 0 & 0 & 0 & 0 & 0 & 0 & 0 \\
\hline \multirow{7}{*}{10} & Original & 曲 & Ht & H & $H$ & H & & 17 & 11 & 9 & 14 & 12 & 6 & 7 & 6.5 & 8 \\
\hline & $1: 10$ & Ht & Htt & Ht & H & H & & 2 & 1 & 1 & 1 & 2 & 0.5 & 1 & 0.5 & 1 \\
\hline & $1: 10^{2}$ & Ht & $H+H$ & H & H & + & $\begin{array}{r}2 \\
(34)\end{array}$ & 0 & 0 & 0 & 0 & 0 & 0 & 0 & 0 & 0 \\
\hline & $1: 10^{3}$ & 世 & Ht & H & H & $\begin{array}{l}35 \\
(\mathrm{x})\end{array}$ & $\begin{array}{ll}0 \\
(3)\end{array}$ & 0 & 0 & 0 & 0 & 0 & 0 & 0 & 0 & 0 \\
\hline & $1: 10^{4}$ & H & HF & H & + & $\begin{array}{l}16 \\
(\mathrm{x})\end{array}$ & $\begin{array}{c}0 \\
(0.5)\end{array}$ & 0 & 0 & 0 & 0 & 0 & 0 & 0 & 0 & 0 \\
\hline & $1: 10^{5}$ & H & $H$ & 63 & 59 & $\begin{array}{l}1.5 \\
(3)\end{array}$ & 0 & 0 & 0 & 0 & 0 & 0 & 0 & 0 & 0 & 0 \\
\hline & $1: 10^{6}$ & 24 & 18.5 & 5.5 & 2 & 0 & 0 & 0 & 0 & 0 & 0 & 0 & 0 & 0 & 0 & 0 \\
\hline
\end{tabular}

Note: Numbers indicate the mean of two tubes.

( ) indicates dysgonic colonies which emerged only after 6 weeks.

Experiment 2: Analysis of streptomycin-resistant colonies. In the previous experiment it was found that colonies appeared in approximately the same numbers on $8 \gamma$ per $\mathrm{ml}$ or higher concentrations. This fact seemed to suggest that mutants resistant to these concentrations are genetically of the same nature as the so-called full-resistant variants. Therefore, the purity of these colonies concerning the resistant cell composition was examined expecting that they are 
possibly composed purely of $1000 \gamma$ per ml resistant cells. The experimental method was just the same as before, using the bacillary suspensions prepared respectively from the subcultures on drug-free Ogawa's medium. The inoculum was, however, limited to two or three kinds of dilution of each bacillary sus? pension. The results were summarized in Table 2 showing the most properly inoculated cases. Contrary to our expectation, the colonies were not always pure, particularly those grown on 8,16 , or $32 \gamma$ per ml streptomycin media contained only a small proportion of high resistant mutants. The colonies obtained on $100 \gamma$ per $\mathrm{ml}$ or slightly higher concentrations were, however, proved to be pure in the resistant cell composition.

Table 2. Purity analysis of streptomycin resistant colonies isolated in a single step

\begin{tabular}{|c|c|c|c|c|c|c|c|c|c|c|c|c|c|}
\hline \multirow{2}{*}{$\begin{array}{l}\text { SM concent. from } \\
\text { which colonies } \\
\text { were recovered }\end{array}$} & \multirow{2}{*}{ 总官 } & \multicolumn{12}{|c|}{ Streptomycin concentration ( $\gamma / \mathrm{ml})$} \\
\hline & & 0 & 4 & 8 & 16 & 32 & 64 & 100 & 200 & 400 & 600 & 800 & 1000 \\
\hline \multirow{3}{*}{$8 \gamma / \mathrm{ml}$} & 1 & 册 & 册 & 29 & 32 & 27 & 24 & (13) & (18) & 0 & $\mathbf{0}$ & 0 & 0 \\
\hline & 2 & 曲 & 冊 & H & + & + & $(130)$ & $(96)$ & $(38)$ & (3) & $\mathbf{0}$ & 0 & 0 \\
\hline & 3 & H & $H$ & + & $\perp$ & 16 & 2 & 0 & 0 & 0 & 0 & 0 & 0 \\
\hline \multirow{5}{*}{$16 \gamma / \mathrm{ml}$} & 1 & 32 & 29 & 36 & 24 & 26 & 21 & (12) & (15) & 0 & 0 & 0 & 0 \\
\hline & 2 & 153 & 164 & 138 & 118 & 83 & 132 & (67) & (8) & 0 & 0 & 0 & 0 \\
\hline & 3 & 81 & 73 & 84 & 88 & 78 & 64 & 82 & (34) & (22) & (3) & (3) & (7) \\
\hline & 4 & + & + & + & + & + & 81 & 83 & 60 & 41 & (4) & (1) & (2) \\
\hline & 5 & 58 & 46 & 50 & 58 & 56 & 73 & 51 & 61 & (4) & 0 & 0 & 0 \\
\hline \multirow{2}{*}{$32 \gamma / \mathrm{ml}$} & 1 & H & $H$ & $H$ & $H$ & $H$ & $H$ & + & + & (76) & (38) & (13) & (8) \\
\hline & 2 & + & + & + & + & + & + & + & + & + & (98) & (31) & (16) \\
\hline \multirow{2}{*}{$64 \gamma / \mathrm{ml}$} & 1 & + & + & + & + & + & + & + & + & + & + & + & + \\
\hline & 2 & 53 & 46 & 59 & 50 & 32 & 48 & 53 & 30 & 13 & (10) & (19) & (16) \\
\hline \multirow{2}{*}{$100 \gamma / \mathrm{ml}$} & 1 & 21 & 22 & 20 & 24 & 18 & 16 & 23 & 23 & 18 & 15 & 21 & 20 \\
\hline & 2 & + & + & + & + & + & + & + & + & + & + & + & + \\
\hline \multirow{2}{*}{$400 \gamma / \mathrm{ml}$} & 1 & 38 & 39 & 31 & 35 & 36 & 41 & 38 & 43 & 32 & 41 & 39 & 33 \\
\hline & 2 & 4 & 4 & 2 & 5 & 3 & 4 & 4 & 3 & 5 & 4 & 6 & 2 \\
\hline \multirow{2}{*}{$1000 \gamma / \mathrm{ml}$} & 1 & 56 & 43 & 58 & 57 & 49 & 56 & 56 & 61 & 48 & 49 & 43 & 49 \\
\hline & 2 & + & + & + & + & + & + & + & + & + & + & + & + \\
\hline
\end{tabular}

Note: Numbers indicate the mean of two tubes.

$($ ) indicates dysgonic colonies.

Experiment 3: Stability of streptomycin resistance. An attempt was undertaken to examine the stability of streptomycin resistance of non-pure and low grade resistant strains as follows. The original H37Rv strain was subcultured at intervals of 2 weeks on slants of Ogawa media containing streptomycin in low concentrations as shown below. 


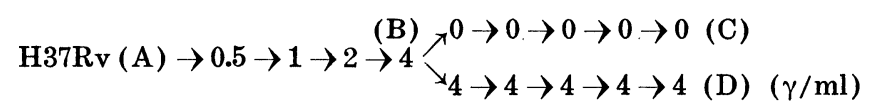

Four cultures (A, B, C and D) were examined of the proportion of mutants resistant to various concentrations of streptomycin. The method was just the same as that in Exp. 1. The results were shown in Fig. 2. It was a remarkable fact that the once markedly increased proportion of high-resistant cells in the culture on $4 \gamma$ per ml was decreased to the original state after being subcultured on the drug-free medium.

Fig. 2. Development of streptomycin resistance during the subculture of $\mathrm{H} 37 \mathrm{Rv}$ in the environment of low concentrations of streptomycin and its stability

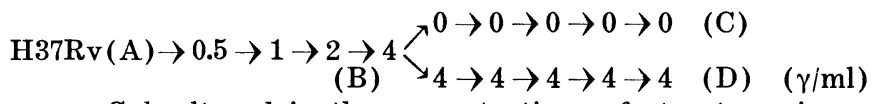

Subcultured in the concentrations of streptomycin as indicated above

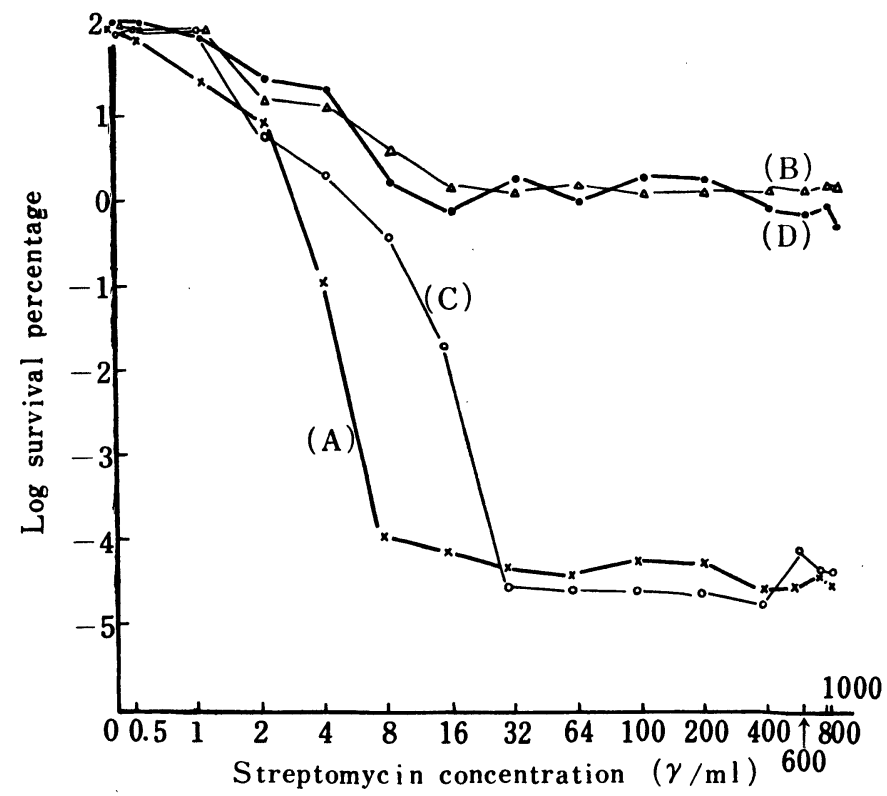

Experiment 4: Directed mutagenic effect of streptomycin upon resting tubercle bacilli. This has been regarded as a key point experiment to determine whether the induced mutation theory can be rational or not. The $\operatorname{results}(9,16)$ reported higherto did not reach the same conclusion. Therefore, the present authors attempted an experiment as follows. Seven kinds of dense bacillary suspension of the same concentration were prepared from the 10 day cultures of H37Rv on the Ogawa medium, being different in diluent and streptomycin concentration as shown below. 
diluent
A Kirchner's basal medium
B Kirchner's basal medium
C distilled water
D distilled water
E distilled water
F distilled water
G distilled water

concentration of
streptomycin $(\gamma / \mathrm{ml})$ environment

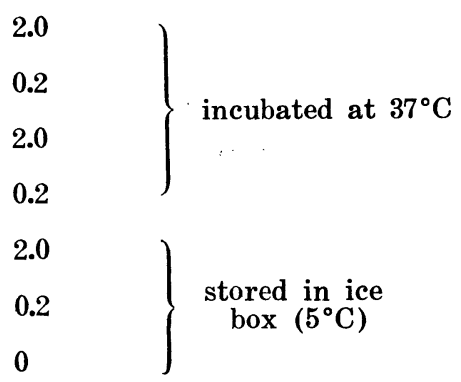

In order to make the bacilli resting to a possible extent, the suspensions described above were prepared using well-washed bacillary mass obtained by centrifuging an aqueous bacillary suspension which had been left to stand at $37^{\circ} \mathrm{C}$ for the precedent 24 hours.

Fig. 3. Induction experiment of streptomycin resistance against washed tubercle bacilli (I)
$\left.\begin{array}{lll}\text { A }: 2 & \gamma & \text { per } \mathrm{ml} \\ \mathrm{B}: 0.2 & \gamma & \text { per } \mathrm{ml}\end{array}\right\}$ Kirchner base medium

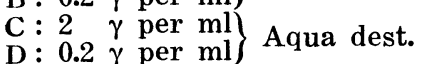
Contact for 3 weeks at $37^{\circ} \mathrm{C}$

$\mathrm{E}:$ the original $\mathrm{H} 37 \mathrm{Rv}$

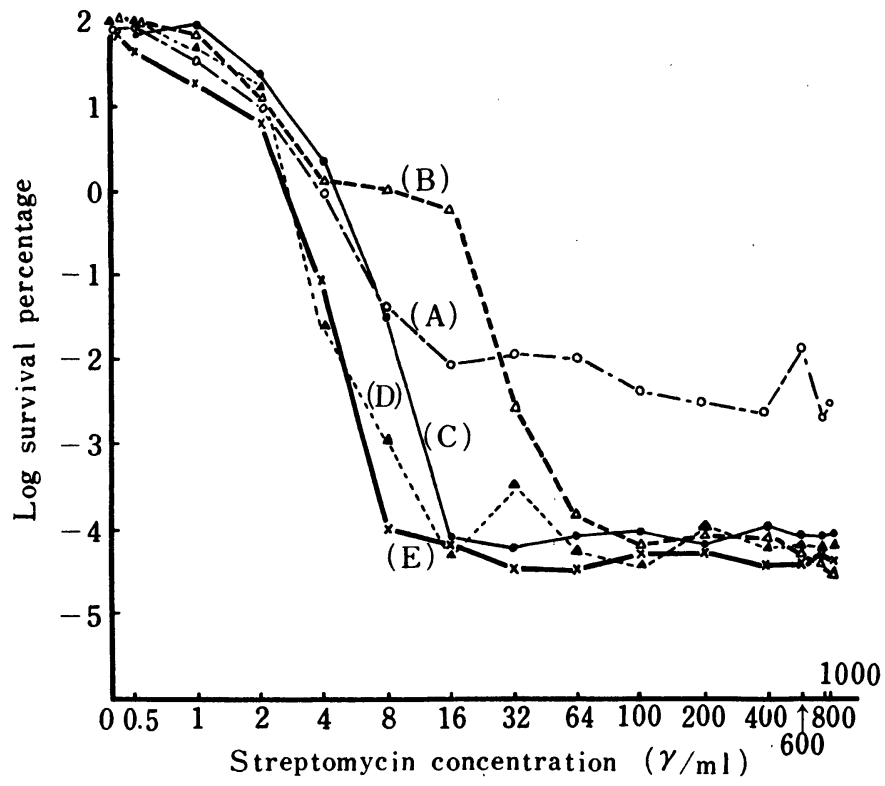

Each suspension was put into to a test tube in the amount of $10 \mathrm{ml}$. Immediately after the preparation, these suspensions were placed in an incubator or an ice box as described above. Of the suspension $G$ the initial proportion of resistant cells was examined at this time. The tubes were left to stand for 
Fig. 4. Induction experiment of streptomycin resistance against washed tubercle bacilli (II)

A : $2 \gamma$ per ml $\mathrm{ml}$ Contact for 3 weeks B: $0.2 \gamma$ per ml Kirchner base medium at $37^{\circ} \mathrm{C}$, then grown

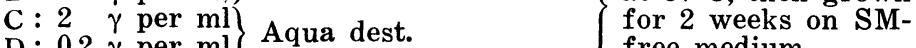
free medium

$\mathrm{E}$ : the original $\mathrm{H} 37 \mathrm{RV}$

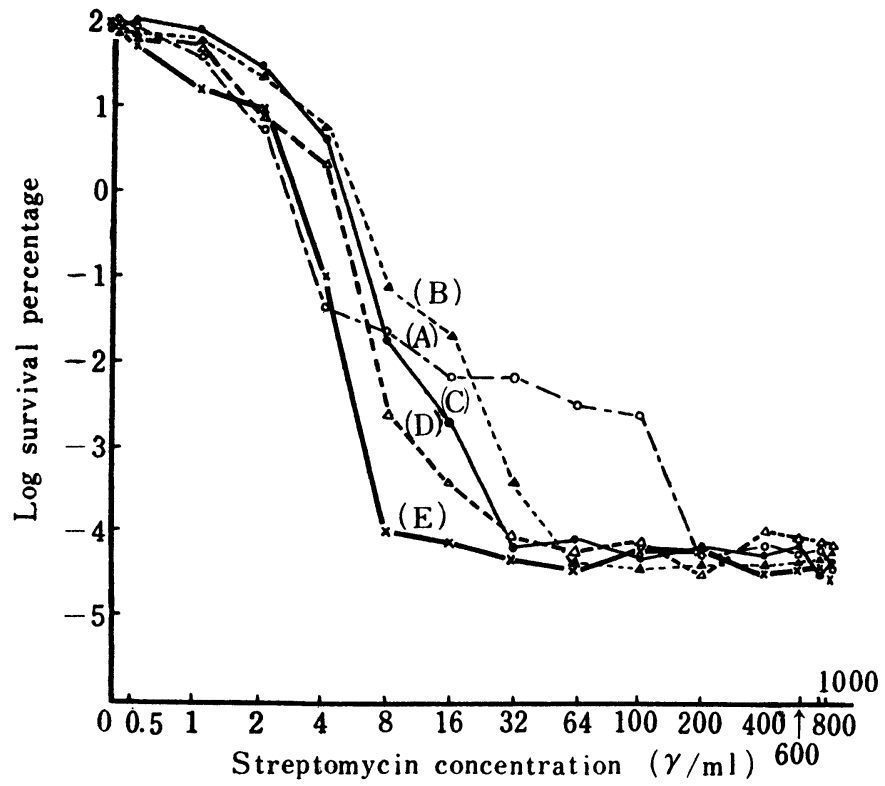

Fig. 5. Induction experiment of streptomycin resistance against washed tubercle bacilli (III)

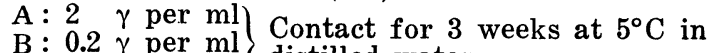
C: SM-free $\int$ distilled water

$\mathrm{D}$ : the original H37Rv

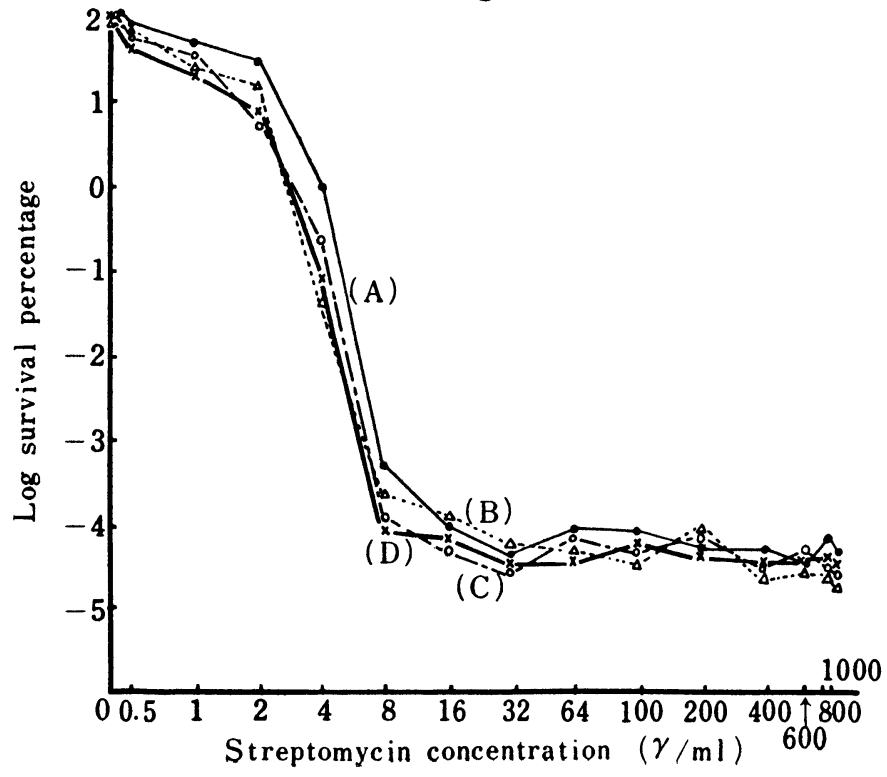


3 weeks. Then, the suspensions were centrifuged at 4000 R.P.M. for 30 minutes. The bacillary mass sedimented was resuspended in distilled water and centrifuged again. The washing in this way was repeated four times in each suspension. Finally they were resuspended in distilled water of the original amount, excepting the bacillary mass in tube $\mathrm{A}$ and $\mathrm{B}$ for which a $5 \%$ Tween 80 solution was used instead of distilled water to disperse grown bacillary clumps as finely as possible. And a test was made to examine resistant cell proportion in these washed bacillary suspensions. The test was then repeated of 2 week cultures of the treated suspensions on the streptomycin-free medium. The results obtained in these serial tests were summarized graphically in Fig. 3, 4, 5, and 6. From Fig. 3 it will be learned that marked increase of resistance was observed in the environment of Kirchner's liquid basal medium where the bacilli can multiply to some extent, particularly in the presence of $2 \gamma$ streptomycin per ml. In $0.2 \gamma$ per $\mathrm{ml}$, however, only the low grades of resistance was developed, even more remarkably than by $2 \gamma$ streptomycin per $\mathrm{ml}$. It may be stated according to our opinion that the difference above was explained from an assumption that

Fig. 6. Induction experiment of streptomycin resistance against washed tubercle bacilli (IV)
A : $2 \gamma$ per $\mathrm{ml}$ Contact for 3 weeks at $5^{\circ} \mathrm{C}$ in
$\mathrm{B}: 0.2 \gamma$ per $\mathrm{ml}$ distilled water, then grown for
C : SM-free $\int_{2}$ weeks on SM-free medium
$\mathrm{D}$ : the original $\mathrm{H} 37 \mathrm{Rv}$

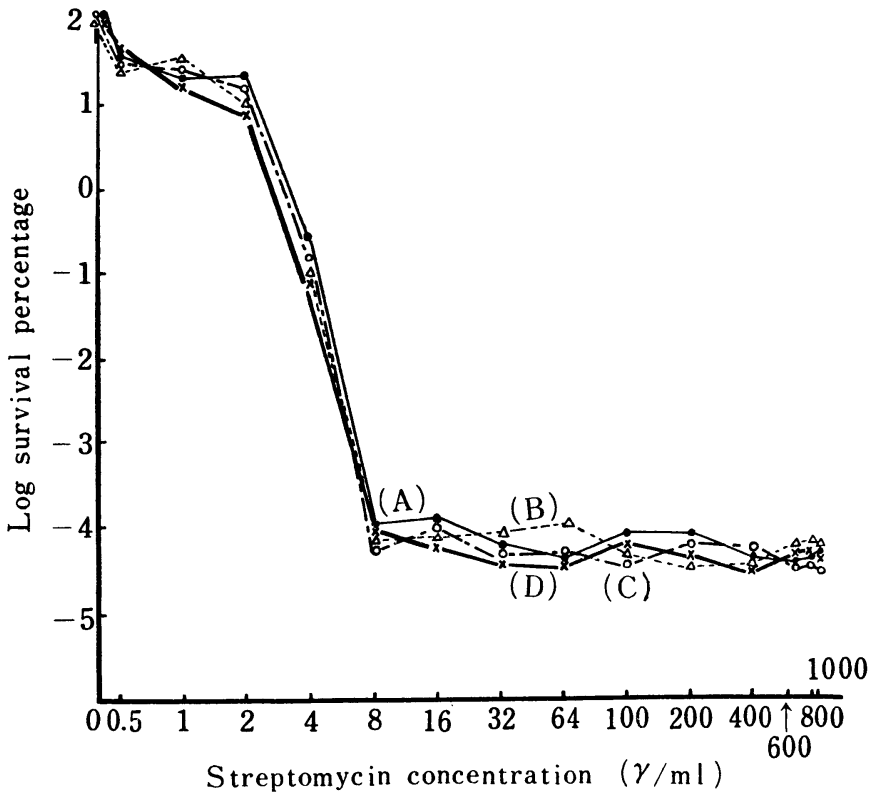

$0.2 \gamma$ per $\mathrm{ml}$ acted only to induce resistance but $2 \gamma$ per $\mathrm{ml}$ acted both to induce resistance and to select naturally occurring mutants. On the contrary, however, definite resistance did not develop significantly by the exposure to streptomycin in distilled water, although $8 \gamma$ per $\mathrm{ml}$ or less resistant cells were increased in 
the proportion after the contact with $2 \gamma$ streptomycin per ml. Then, Fig. 4 showed that even when phenolag was given resistance did not develop in the bacilli treated with streptomycin in distilled water. Furthermore, it was known that once developed resistance (Curve A in Fig. 3) by $2 \gamma$ streptomycin per $\mathrm{ml}$ in Kirchner liquid medium was decreased during this phenolag. Fig. 5 and Fig. 6 added the further evidence that the so-called directed mutagenic action was not effective to resting tubercle bacilli.

\section{Discussion}

In order to prove that streptomycin acts upon tubercle bacilli as a mutagen to make them resistant to it, that is to say, the directed induced mutation, the following two experiments are necessary; the first is to observe the resistance increase by subculturing the bacilli on the medium in a low concentration of streptomycin in which selection does not operate; the second is to confirm that when resting tubercle bacilli were exposed to streptomycin for a certain period of time the proportion of resistant cells is enlarged in a population of them. The experiments reported in this paper, however, could not demonstrate the mutagenic effect of streptomycin upon tubercle bacilli of resting state. The effect was observed only in the environment in which the bacilli can multiply. When exposure to streptomycin was made in distilled water at $37^{\circ} \mathrm{C}$, the occurrence rate of lowly resistant cells was slightly increased. But even in this environment we can not expect that the bacilli were present in the completely resting state. Because, as already pointed out by Ushiba and Watanabe(16), growth-supporting substances will be liberated into diluent from autolysed bacillary bodies in such a dense bacillary suspension as used in the present experiments. Ushiba and Watanabe ${ }^{(16)}$ who studied on this problem using Salmonella enteritidis could not acknowledge the directed mutagenic action of streptomycin in the exposure experiment both at $37^{\circ} \mathrm{C}$ and $5^{\circ} \mathrm{C}$ during various periods of time. On the other hand, Yokota ${ }^{(9)}$ succeeded to observe the mutagenic action of streptomycin in the experiment using Staph. aureus, E. coli and M. tuberculosis. Precise survey of his data, however, indicates that the effect was manifested principally at $37^{\circ} \mathrm{C}$ and very scarcely at $0^{\circ} \mathrm{C}$. And if the effect was perceived at $0^{\circ} \mathrm{C}$, streptomycin acted only to increase the proportion of cells of low-grade resistance. Therefore, it did not appear that the complete proof was given by his experiment for the directed mutagenic action of streptomycin. To make the matter more difficult to understand, Yokota presented the data that a bacterial population of resting Staph. aureus $209 \mathrm{P}$ suspended in phosphate buffer was killed completely being exposed to streptomycin of $25 \gamma$ per $\mathrm{ml}$ at $37^{\circ} \mathrm{C}$ before receiving the mutagenic action under consideration, but that of resting E. coli B 19 in the same environment was killed only to $1 / 50$ of the original number of viable cells by streptomycin of $100 \gamma$ per ml accompanying the almost complete acquisition of $1000 \gamma$ per ml resistance. It has been generally believed that penicillin and streptomycin exert their bactericidal effect only upon 
dividing bacteria. Therefore, from the finding that streptomycin of $25 \gamma$ per $\mathrm{ml}$ exerted such a marked bactericidal effect, it is very doubtful that his experiment was made in the truely resting state of the bacilli. In this connection, the result that the mutagenic action was acknowledged in the cases using much lower concentrations of streptomycin such as 2.5 or $0.25 \gamma$ per $\mathrm{ml}$ in the same experiment of Staph. aureus should be reexamined. Generally speaking, the mutagenic agents which have been hitherto reported were of the nature that mutations induced by them are manifested only after the repetition of bacterial cell-division. In other words, those mutagens are considered to produce the so-called endpoint mutation requiring phenolag. What Yokota insisted, however, is not the endpoint mutation, but the zeropoint mutation. If this is true, it may be a very rare example in the genetical field. Concerning this problem, it will be worthy of mentioning that DNA of streptomycin-resistant avian tubercle bacilli can act upon streptomycin-sensitive ones to make them resistant only in the environment where the bacilli can multiply by cell division(17). Yudkin(18) also stated that the acquisition of streptomycin resistance can not be made without celldivision.

The next point to be discussed is the stability of streptomycin resistance. This problem, however, must be always considered as the change of mixing proportion of cells resistant to various concentrations of the drug in a given bacterial population. Fig. 2 in this paper showed that the strain H37Rv subcultured on a $4 \gamma$ per ml streptomycin medium contained resistant cells to $8 \gamma$ per ml and higher concentrations up to $1000 \gamma$ per $\mathrm{ml}$ in an increased proportion. After being brought back into the streptomycin-free medium and subcultured for several generations, however, the mixed proportions of those resistant cells were decreased to the level of the original $\mathrm{H} 37 \mathrm{Rv}$ not exposed to streptomycin previously, although the proportion of cells of low-grade resistance was still kept high. If Fig. 3 and Fig. 4 are compared each other, the similar phenomenon will be observed. These phenomenon will be easily understood by such a consideration that the rate of cell division may be different among those resistant cells in the manner as the lower the degree of resistance is, the higher the dividing rate is. Ushiba(16) pointed out that there are two types of resistant cells, dysgonic and eugonic, and the former type of cells often produce the latter in quite an incidental way. He further added that eugonic resistant cells are generally lower in the degree of streptomycin resistance than dysgonic resistant cells. Therefore, when resistant cells are subcultured in the streptomycin-free medium, the resistance is often decreased. On the other hand, however, streptomycin resistance has been generally considered to be extremely stable even when subcultured in the streptomycin-free medium. Ushiba designated this type of resistant cells as streptomycin indifferent, differentiating from the resistant cells stated above. This way of thinking appears to be convenient for understanding the phenomenon of streptomycin resistance. Table 2 in this paper demonstrated that the emergent colonies on the medium containing streptomycin in a concen- 
tration higher than $100 \gamma$ per $\mathrm{ml}$ can be regarded to be purely composed of $1000 \gamma$ per ml resistant cells. Attention must be directed to the fact, however, that those colonies shown in Table 2 had been once subcultured on streptomycinfree Ogawa's medium before the purity test was conducted. Hence, the proportion of resistant cells in those colonies may have changed during that subculture, particularly in those grown on $64 \gamma$ per ml or less streptomycin medium. In this connection, according to the hypothesis of Ushiba, the strains originating from the colonies isolated on the medium containing streptomycin $100 \gamma$ per ml or higher concentrations are to be called "streptomycin indifferent", and those from $64 \gamma$ per $\mathrm{ml}$ or less streptomycin medium are to be called "streptomycin resistant". In any way, these colonies were isolated in one step. So, a question will be arisen as follows. For instance, whether $1000 \gamma$ per ml resistant strains obtained by step-wise exposure are the same or not as $1000 \gamma$ per ml strains isolated in one step. For this question a definite proof is not yet given. Then, discussion will be continued concerning Table 1. As shown in this table, colony formation was observed in almost the same numbers on the slants of streptomycin varying in concentrations from 8 to $1000 \gamma$ per ml. This tendency was just the same as that reported in our previous report(14). At that time a view was stated that tubercle bacilli resistant to streptomycin of $10 \gamma$ per ml or to higher concentrations are to be equally designated as complete or full resistant. As described just above, however, this view must be changed here. The table shows us one more important thing to understand the origin of streptomycin resistance, namely, the inoculation with a 1:10 diluted bacillary suspension produced colonies on streptomycin slants in the numbers of approximately 1/10 of those appeared when inoculated with the undiluted suspension. This observation seems to support the spontaneous mutation and selection theory in the meaning that streptomycin did not operate to modify this natural tendency.

On the other hand, we know that streptomycin resistance can develop to a high level even when microorganisms are subcultured on the medium containing streptomycin in such a concentration that does not operate to select the resistant cells of the lowest grade. Yokota(9) has clearly shown this phenomenon. In this paper it was described that a culture grown on $0.5 \gamma$ per ml streptomycin Ogawa solid medium had an increased proportion of high resistant cells. In addition, it was found that when the bacilli were exposed to streptomycin of $0.2 \gamma$ per ml in the environment of Kirchner's liquid medium at $37^{\circ} \mathrm{C}$ the proportion of resistant cells of low grades $(8,16$, and $32 \gamma$ per $\mathrm{ml})$ was increased. A more remarkable example was observed by us, as reported in another paper(19), that $E$. coli O-1 from which resistant cells to $1000 \gamma$ per $\mathrm{ml}$ streptomycin were never isolated in one step from any large population came to contain them in a higher proportion after serial subculture on $0.5 \gamma$ per ml streptomycin. Watanabe(4) presented an idea "relative selection due to relative inhibition" for the explanation of step-wise increase of resistance. The present authors observed, however, that relative inhibition of the growth of $E$. coli O-1 did not occur due 
to $0.5 \gamma$ per $\mathrm{ml}$ streptomycin in the point of size of colonies and rapidity of colony formation. Then, how the phenomenon above can be explained? In a previous report(20) it was suggested that tubercle bacilli do not cease to multiply immediately after the contact with streptomycin of even the lethal dose. This fact had been also reported by Stenderup(24) in E. coli. Particularly, sublethal amount of streptomycin acts on tubercle bacilli to permit the formation of microscopical colonies but to prevent their development into macroscopical colonies. Therefore, it will be not impossible to think that tubercle bacilli are effected by the possibly mutagenic action of streptomycin during the process of the microscopical-colony formation. Because, a situation similar to the endpoint mutation can be considered in this case. Then, the authors should like to think that the directed mutagenic action of streptomycin suggested by several investigators may be effective only to dividing tubercle bacilli at the sublethal concentrations of streptomycin, and not to resting tubercle bacilli. When the bacilli increase step by step in the resistance, the mechanism described above may be operating. Recently, Goldberg and Morgan(21) reported on a peculiar effect of sublethal or non-inhibitory concentrations of streptomycin that they caused change in the morphology of cells (Erwinia anuylovora) producing a series of lumps (supposed nuclei) in their cytoplasma. Then, Watanabe(16) reported that the proportions of streptomycin resistant cells of low grades were increased in a population of Salmonella enteritidis irradiated with ultraviolet rays. He added, however, that it is not certain whether this was caused by the induced mutation due to ultraviolet rays or by selection of cells resistant both streptomycin and ultraviolet rays.

Now, we should like to point out a very analogous property between streptomycin and irradiation. Luria(22) has ever reported that though failing to give rise to a visible colony, a bacteria which has been killed by radiation may divide once or twice after sown onto a nutrient medium. This observation suggests that the death of an irradiated bacterium occurs at or following cell divisions. The cause may be an effect of radiation on the genetical apparatus, and the lethal mutation theory has its experimental background in this phenomenon. In this meaning, radiation exerts an influence upon bacteria similar to the streptomycin effect descrived before. Yudkin(18) stated that bacterial resistance to chemotherapeutic agents will not occur without bacterial multiplication, and presented a hypothesis that the asymmetrical distribution of genetic material is caused at cell-division and the clonal-variation with selectoin subsequently occurs in the presence of streptomycin. Kamijo(23) studied on the morphological change of $E$. coli caused by streptomycin with the result that the nuclear substance of the bacilli is modified by the subinhibitory concentration of streptomycin to take a dotted appearance. This observation indicates that streptomycin acts upon bacterial nuclei and possibly also on the genetical material. Therefore, it will be not impossible to think that the asymmetrical distribution of genetic material speculated by Yudkin(18) may be caused by streptomycin. On the other 
hand, Demerec(1), who has been insisting the spontaneous mutation and selection theory in bacterial resistance to chemotherapeutic agents, classified the pattern of acquisition of drug-resistance into penicillin-type and streptomycin-type, and presented a theoretical explanation that there are many genes controlling drug resistance of equal potency for the penicillin-type but of different potency for the streptomycin-type. The development of streptomycin resistance in $E$. coli as reported by us in another paper(19), however, did not take the socalled streptomycin type, but it was the penicillin type. Finally, summarizing what has been stated above, the view of the present authors will be presented here.

First of all, as suggested by Ushiba and Watanabe(16), it is convenient for understanding of streptomycin resistance to postulate that there are two types of streptomycin-resistant cells; streptomycin-indifferent (Ushiba and Watanabe) and streptomycin-resistant. And the former cells will occur by the spontaneous mutation and the latter will be produced by the induced mutation due to the contact with streptomycin. Unlike the view of Yokota, however, we believe that the induced mutation is produced only when subinhibitory or sublethal concentrations of streptomycin act upon tubercle bacilli in the environment where the bacilli can multiply, and not upon completely resting cells.

\section{SUMMARY}

Origin of streptomycin resistant variants of tubercle bacilli was investigated in vitro experiments. High mutant cells isolated in one-step on streptomycin containing medium appeared to be produced by the selection of the spontaneously occurring mutant cells. On the other hand, when the bacilli develop their resistance step by step in serial subculture in the medium containing increasingly higher concentrations of streptomycin, mutagenic effect of streptomycin may be operating to produce such mutants. Because, even when the bacilli were subcultured in the environment with streptomycin at a concentration which does not operate to select the resistant cells of the lowest grade, a marked increase of proportions of high resistant cells was observed. The mutagenic effect of streptomycin as above was, however, considered to be effective only when subinhibitory or sublethal concentrations of streptomycin act upon tubercle bacilli in the environment when the bacilli can multiply, and not upon resisting tubercle bacilli. This view was developed from our previous finding that tubercle bacilli did not cease to multiply immediately after the contact with sublethal concentrations of streptomycin but continue cell division to some extent to form a microscopical colony. In this point, the mutagenic action of streptomycin was thought to be analogous to radiation effect as suggested by Luria.

\section{REFERENCES}

1) Demerec, M.: Origin of bacterial resistance to antibiotics. J. Bact., 56, 63-74, 1948.

2) Newcombe, H. B., and Hawirko, R.: Spontaneous mutation to streptomycin resistance and dependence in $E$. coli. J. Bact., 57, 565-572, 1949. 
3) Yegian, D., and Vanderlinde, R. J.: The resistance of tubercle bacilli to chemotherapeutic agents. Am. Rev. Tuberc., 61, 483-507, 1950.

4) Watanabe, T.: Genetic studies on the mechanism of acquired streptomycinresistance in microorganisms. Keio J. Med., 3, 193-213, 1954.

5) Eagle, H., Fleischman, R., and Levy, M.: Development of increased bacterial resistance to antibiotics. J. Bact., 63, 623-638, 1952.

6) Gibson, M. I., and Gibson, F.: Development of resistance to dihydrostreptomycin by Bacterium coli. Nature, 167, 113-114, 1951.

7) Stenderup, A.: Development of streptomycin resistance in E. coli. Acta Path. Microbiol. Scand., 33, 195-201, 1953. Studies on the action of streptomycin on E. coli Acta Path. Microbiol., 32, 453-464, 1953.

8) Linz, R.: Sur le mechanisme de l'action de la streptomycin. II. La resistance a la streptomycin. Ann. Inst. Pasteur, 78, 105-114, 1950.

9) Yokota, K.: On the mechanism of drug-resistance. Jap. J. Bact., 10, 261-267, 317-319, 419-425, 509-514, 651-656, 1955 (in Japanese).

10) Ushiba, D.: The 2nd Assembly of the Eastern Branch of the Japanese Chemotherapy Association., Oct., 1955, Tokyo.

11) Akiba, T.: Development of drug resistance in bacteria and induced mutation. New Field of Bacteriology. Igakushoin Press Co., 204-221. 1953 (In Japanese).

12) Kimino, T.: Method to prevent drug-resistance of bacteria. Saishin Igaku, 9, 167-175, 1954 (in Japanese).

13) Katsunuma, N.: Induced mutation to drug resistance and the induced mutation to drug resistance and the mechanism of streptomycin resistance viewed from it. Biological Science, 7, 79-86, 1955 (in Japanese).

14) Yanagisawa, K., Kanai, K., Shiga. Y., and Ito, F.: Studies of the streptomycin-resistance developed in tubercle bacilli (BCG). Jap. Med. J., 4, 99-111, 1951.

15) Kanai, K., Nakamoto, T., and Yanagisawa, K.: In vitro experiments of the development of the streptomycin resistance in different strains of Mycobacterium tuberculosis. Jap. J. Med. Sci. Biol., 6, 365-370, 1953.

16) Ushiba, D., and Watanabe, T.: Mechanism of increase and decrease of streptomycin resistance of bacteria. Jap. J. Bact., 9, 349-353, 1954; 10, 231-237, 1955.

17) Sugiyama, M., and Tanaka, S.: Biochamical and genetic studies on the appearance of streptomycin resistant organisms in tubercle bacilli. Kekkaku, $29,23-33,1954$.

18) Yudkin, J.: Origin of acquired drug resistance in bacteria. Nature, 171, 541$546,1953$.

19) Kanai, K., Katsuyama, S., and Yanagisawa, K.: in press.

20) Kanai, K.: Studies on the antibacterial action of streptomycin against tubercle bacilli as a possible mitotic poison, with particular reference to the development of drug-resistance. Jap. J. Bact., 10, 177-183, 1955 (in Japanese).

21) Goldberg, H. S., and Morgan, B. S.: Change in bacterial morphology as a result of low concentration of streptomycin. J. Bact., 68, 507, 1954.

22) Luria, S. E.: Action des radiations sur le Bactérium coli. Compt. rend., 209, 604-606, 1939.

23) Kamijo, K.: Morphological studies on the effect of antibiotics on the bacterial cell. Jap. J. Bact., 9, 193-197, 1954.

24) Stenderup, A.: Studies on the effect of streptomycin on $E$. coli by direct agar microscopy. Acta Path. Microbiol. Scand., 32, 281-289, 1953. 